\title{
ANALYSIS OF THE TIME SERIES OF STATION COORDINATES - A COMPARISON OF THE NETWORK AND PPP APPROACH
}

\author{
Jan KOSTELECKÝ ${ }^{1,2) *}$, Jan DOUŠA ${ }^{1)}$, Jakub KOSTELECKÝ ${ }^{1)}$ and Pavel VÁCLAVOVIC ${ }^{1,3)}$ \\ ${ }^{1)}$ Research Institute of Geodesy, Topography and Cartography, p.r.i., GO Pecný, CZ-251 65 Ondřejov \\ ${ }^{2)}$ Institute of Geodesy and Mine Surveying, Faculty of Mining and Geology, TU Ostrava, 17. listopadu 15, CZ-708 33 Ostrava Poruba \\ ${ }^{3)}$ Department of Geomatics, Faculty of Civil Engineering, CTU in Prague, Thákurava 7, CZ-166 29 Praha 6
}

*Corresponding author's e-mail: mailto:kost@fsv.cvut.cz

\begin{tabular}{l} 
ARTICLE INFO \\
\hline Article history: \\
Received 15 January 2015 \\
Accepted 12 May 2015 \\
Available online 22 May 2015 \\
\hline Keywords: \\
GNSS \\
Time series analysis \\
Station velocities
\end{tabular}

\section{INTRODUCTION}

The goal is the analysis of time series of coordinates of a selected set of 14 EPN (EUREF Permanent Network) stations over a long time interval. The coordinates were determined using two methods. First, the classical „network solution“"was used where the GNSS observations are processed by baseline vectors connecting two stations and tied to selected "fiducial stations" using differenced observations. Second, the PPP (Precise Point Positioning) method was applied, where the single station coordinates are determined directly from all available GNSS observations carried out at this station only using precise final orbits and precise satellite clock corrections. In both cases the Bernese v. 5.2 software was used for the processing and the computations were carried out in the ITRF2008 terrestrial reference frame.

The resulting coordinate time series were analysed using the Vaníček's unharmonic analysis (Wells and Vaníček, 1978 or Kostelecký and Karský, 1987) slightly modified by Vondrák (1970, 1977). This analysis makes it possible to determine the trend as well as the most significant periods. The main goal is to compare the results obtained from the two processing methods as to the time development of coordinates and also the most significant detected periods.

\section{DATA ANALYSIS}

\subsection{NETWORK SOLUTION}

The network solution is based on the doubledifferenced solution on the pre-defined baselines. The solution is consistent over the period 1996/01 -
2013/12. The entire EUREF-EPN (250+ stations) was included in the processing. The distribution of the stations can be seen from Figure 1. In processing the following parameters were used: parameters of IERS2010 compliant models, I08 satellite antenna and phase centers and ITRF2008 reference frame. For initial coordinates of fiducial stations the NNT (No Net Translation) minimum constraints were applied. The datum was realized on a daily and weekly solution through a selected set of iteratively controlled fiducial stations. A multi-year combination was generated for station coordinates, velocities and discontinuities and residuals analysis.

\subsection{PPP SOLUTION}

The Precise Point Positioning solution is based on a "direct non-differenced position determination". The processing was carried out using the Bernese GPS Software Version 5.2 following processing steps recommended by software developers and provided with the software installation. This solution is consistent over the period 2000/01 - 2007/12 and was applied for selected stations only: BOGO, BOR1, DRES, GOPE, GRAZ, HERS, HFLK, KIRU, NICO, ONSA, POTS, REYK, TUBI, WTZR. As in the network solution, the precise products for satellite orbits, clocks, and Earth Rotation Parameters (ERP) were taken from the reprocessing reprol provided by the International GNSS service (IGS). Such products were selected for their consistency along the processing period. The Differential Code Biases (DCB) were taken from the CODE solution. The reference frame was taken from the orbits and the sampling interval $300 \mathrm{~s}$ was used for the solution. All 
EUREF Permanent Tracking Network

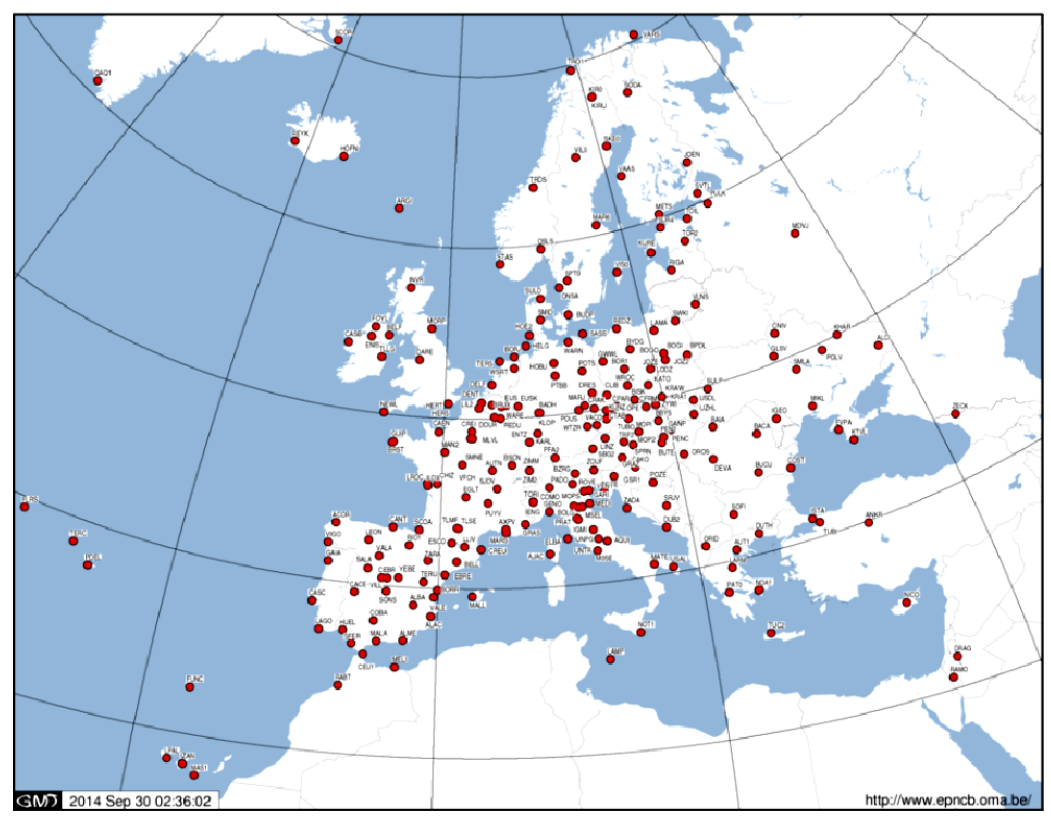

Fig. 1 Distribution of the stations used for the network solution.

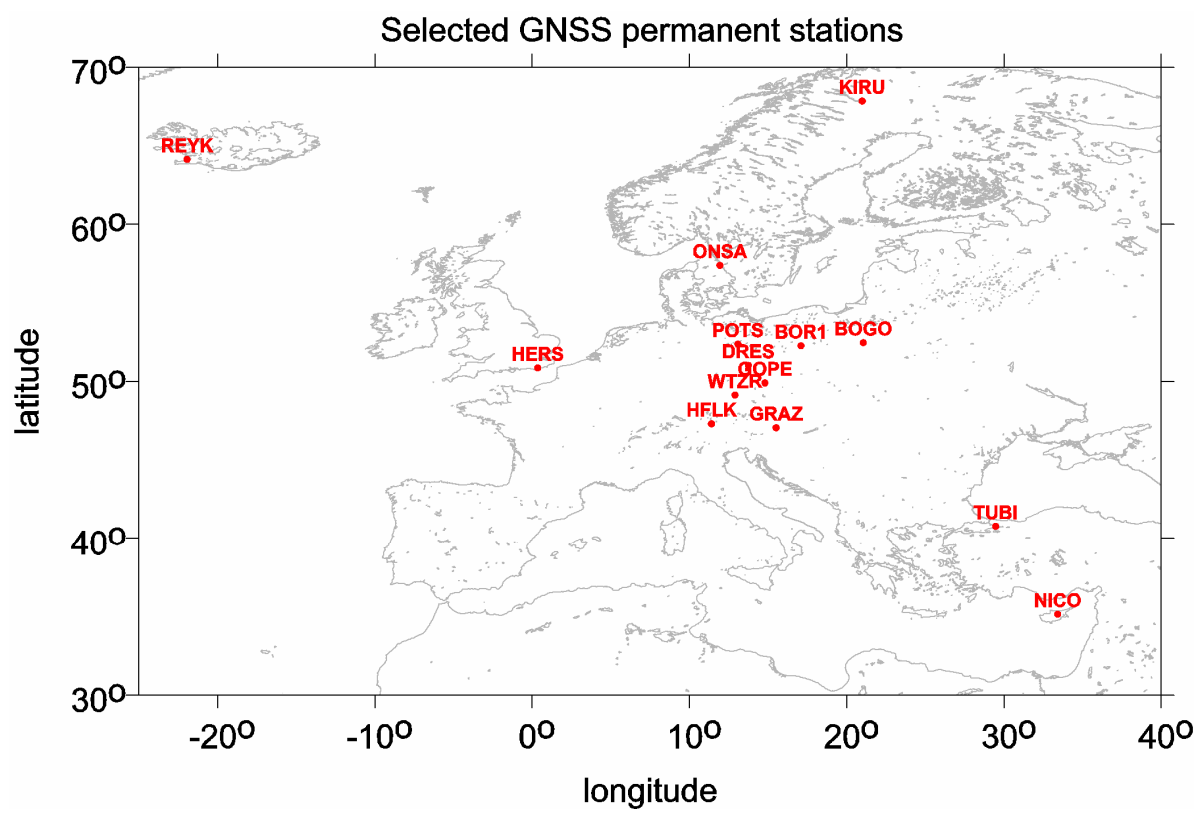

Fig. 2 Distribution of permanent stations used in PPP solution.

models in the processing were applied according to the IERS2010 conventions. The type antenna calibrations I08 were applied for satellite and receiver phase center offsets and variations. Zenith total delays were estimated in PPP as well as in the network solution. Moreover, ambiguities were solved as float values in the PPP because phase biases were not applied. The solution is based only on GPS observations obtaining one solution per day. The distribution of selected GNSS permanent stations used in the PPP solution is displayed in Figure 2.

\section{METHOD OF ANALYSIS}

Let have the set of homogenized quantities $H$ are considered the only realization of random process. Drawing on the physical characteristics of the process of determining quantity $H$, our realization of the deterministic process can be expressed in terms of a function of time $t$.

$H_{i}(t)=\sum_{k=0}^{K} A_{k} t_{i}^{k}+\sum_{j=1}^{J} R_{j} \cos \left[2 \pi f_{j} t_{i}-{ }^{\circ} \phi_{j}\right]+s_{i}(t)$ 
where $s_{i}(t)$ has a normal distribution with dispersion $\sigma^{2}$ and mean value $\mu_{s}(t)=0, A_{k}$ are polynomial coefficients, $f_{j}=\frac{1}{P_{j}}$ is the frequency, $P_{j}$ the period (in days), $R_{j}$ amplitude, and ${ }^{\circ} \phi_{j}$ the phase. We shall seek the optimum estimate of these parameters, preserving the ergodicity condition and the properties of realization (1) of the process. We shall also introduce the notations

$$
\sum_{k=0}^{K} A_{k} t_{i}^{k}=Q_{k}, \quad R_{j} \cos \left[2 \pi f_{j} t_{i}-{ }^{\circ} \phi_{j}\right]=Q_{j}
$$

In seeking the hidden periods, one usually uses periodograms of the type

$$
I(f)=\left(2 \pi T^{-1}\right)\left|\int_{0}^{T} x(t) \exp (-i t f) d t\right|^{2}
$$

as a criterion, in which $f$ is the frequency, $x$ the continuous realization of the random process in interval $T, i=\sqrt{-1}$. However, we have used a slightly different procedure, Vaníček (Wells and Vaníček, 1978) unharmonic analysis, modified by Vondrák (1977).

According to Vaníček, the optimum normalized spectrum, using (2) reads

$\sigma\left(x_{i}\right)=1-\left[\frac{\rho\left(x_{i}-Q_{k}, Q_{j}\right)}{\rho\left(x_{i}, Q_{k}\right)}\right]$

where

$\rho(F, G)=\sum_{t \in T}[F(t)-G(t)]^{2}$

defines the metric of the two function $F$ and $G$ defined on $T$. The coefficients $A_{k}$ of polynomials $Q_{k}$ are determined under assumption of independence, so that

$\rho\left(x_{i}, Q_{k}\right)=\min$.

And, similarly, coefficients $R_{j}$ and ${ }^{\circ} \phi_{j}$ from $Q_{j}$ are determined for every frequency $f \in \Omega$, where $\Omega$ is a set of reasonably optional frequencies, so that

$\rho\left(x_{i}-Q_{k}, Q_{j}\right)=\min$.

Coefficients $R_{j}, j=1,2, \ldots \ldots, J$, are thus functions of frequency $f_{j}$, and, as regards $\sigma\left(x_{i}\right)$, it is easy to prove that for the given realization of the process

$\sigma\left(x_{i}\right): \Omega \rightarrow\langle 0,1\rangle$.

The separate maxima of function $\sigma\left(x_{i}, t\right)$, the spectrum peaks, determine the frequencies which make the principal contribution to the overall variation of function $x_{i}(t)-Q_{k}(t)$. Conditions (6) and (7) lead to classical method of least squares, $K$ being determined in (1) and (2) from the apriori known character of the function, or from experimental computations.

Vondrák's (1977) modification of the method is in the following:

(a) The optimum normalized spectrum is expressed as the function

$g^{2}(f)=\sigma(f)$

(b) Consequently, the values of the normalized spectrum are defined as follows:

$g\left(f_{j}\right)=\sqrt{\left\{1-\left[\frac{\rho\left(x_{i}-Q_{k J}, Q_{j}\right)}{\rho\left(x_{i}, Q_{k J}\right)}\right]\right\}}$

where

$Q_{k J}=\sum_{k=0}^{K} A_{k} t^{k}+\sum_{j=1}^{J} R_{j} \cos \left[2 \pi f_{j} t-{ }^{\circ} \phi_{j}\right]$.

Function $g(f)$ is realized by a set of discrete values $g\left(f_{j}\right), f_{j} \in\left\langle f_{\min }, f_{\max }\right\rangle$, where $f_{\min }$ and $f_{\max }$ are empirically optional. The values $g\left(f_{i}\right)$ can be calculated from (10) in each case for commonly adjusted parameters $A, R,{ }^{0} \Phi$ from (11) under conditions similar to (6) and (7) with values of $f_{j}=\frac{1}{P_{j}}$ set in advance. Moreover, $J=J_{0}+J_{1}, J_{0}$ being the number of frequencies $f_{j}$ imposed in advance, and $J_{1}$ the number of frequencies determined earlier. The spectral analysis is applied gradually in each case with a $Q_{k J}$ newly formed from (11) for $f_{j}$ from the whole interval. For the next iteration step $J$ is increased by 1 and the frequencies for which $g\left(f_{j}\right)$ was maximum is added to the set of frequencies earlier. After the last iteration step one should have

$x_{i}(t)-Q_{k J}(t)=s_{i}(t)$,

and the set $\left\{s_{i}(t), t \in T\right\}$ should converge to the normal distribution. In the computer program this is effected by the condition, $g\left(f_{j}\right)_{\max }\left\langle g_{0}, g_{0}\right.$ being selected empirically by deliberating the physical nature of the phenomenon being studied, of by means of model test.

(c) Last modification resulted in speeding up the computation of the coefficients of polynomials (11) by omitting the quite rigorous (with a view to the discrete realization of the set with a generally non-uniform data distribution) calculation of 
Table 1 List of analyzed stations.

\begin{tabular}{lllc}
\hline \multicolumn{1}{c}{ acronym } & \multicolumn{1}{c}{ localization } & \multicolumn{1}{c}{ character of locality } & $\begin{array}{c}\text { results are in } \\
\text { Table \# }\end{array}$ \\
& & & 2 \\
BOGO & Borowa Góra, Poland & stable part of Eurasian Plate & 3 \\
BOR1 & Borowiec, Poland & stable part of Eurasian Plate & 4 \\
DRES & Dresden, Germany & stable part of Eurasian Plate & 5 \\
GOPE & Pecny, Ondrejov, Czech Rep. & stable part of Eurasian Plate & 6 \\
GRAZ & Graz, Austria & British Isles & 7 \\
HERS & Hailsham, United Kingdom & high mountain station & 8 \\
HFLK & Hafelekar, Innsbruck, Austria & Scandinavian plate & 9 \\
KIRU & Kiruna, Sweden & border zone of Euro-Asian plate & 10 \\
NICO & Nicosia, Cyprus & Scandinavian plate & 11 \\
ONSA & Onsala, Sweden & stable part of Eurasian Plate & 12 \\
POTS & Potsdam, Germany, & North-American plate & 13 \\
REYK & Reykjavik, Iceland, & area of intensive seismicity & 14 \\
TUBI & Gebze, Turkey & stable part of Eurasian Plate & 15 \\
WTZR & Wettzell, Germany & & \\
\hline
\end{tabular}

the summations of the type $\sum_{i} t_{i} \cos \omega, t \in T$, which is replaced with analytically computed integrals $\int_{0}^{T} t \cos \omega d t$.

\section{RESULTS OF ANALYSIS}

As already mentioned above, the time series analysis was performed for 14 selected permanent stations the coordinates of which were determined by two methods - the network solution based on differenced observations and the precise point positioning. All the analysed stations are located in the areas that are interesting from the point of view of geodynamics - see Table 1

The results of analysis are given in the following tables. Each table contains for both processing methods
- $\quad$ rms dispersion $\sigma_{0}$ of analyzed time series for the individual component $\mathrm{N}$ (south-north), E (west east), U (up)

- time interval of network (NET) solution, taken for the analysis

- value of the linear trend for $\mathrm{N}, \mathrm{E}, \mathrm{U}$ for the described interval of PPP solution

- $\quad$ amplitude of the annual (one year) period

- "long periodic terms" means period greater than one year

and also the differences between the network (NET) and PPP solutions.

RMS error of the trend in all coordinates is between $0.01 \mathrm{~mm} /$ year and $0.04 \mathrm{~mm} /$ year and RMS error in determined amplitudes is between $0.2 \mathrm{~mm}$ and $0.3 \mathrm{~mm}$.

Table 2 - result of analysis.

\begin{tabular}{|c|c|c|c|c|c|c|c|}
\hline \multirow[t]{2}{*}{ BOGO } & \multirow{2}{*}{$\begin{array}{c}\sigma_{0} \\
\mathrm{~N}, \mathrm{E}, \mathrm{U} \\
{[\mathrm{mm}]}\end{array}$} & \multicolumn{3}{|c|}{$\begin{array}{c}\text { linear trend }[\mathrm{mm} / \mathrm{y}] \\
\text { NET solution } 1996.7-2012.1\end{array}$} & \multicolumn{3}{|c|}{ amplitude of annual period [mm } \\
\hline & & $\mathrm{N}$ & $E$ & $\mathrm{U}$ & $\mathrm{N}$ & $\mathrm{E}$ & $\mathrm{U}$ \\
\hline NET & $3.9,2.5,6.7$ & 14.6 & 21.0 & -0.2 & - & - & - \\
\hline PPP & $3.5,4.5,7.4$ & 14.6 & 20.4 & -0.4 & - & - & 5.1 \\
\hline diference & & 0 & 0.6 & 0.2 & \multicolumn{3}{|c|}{ long periodic changes } \\
\hline
\end{tabular}

Table 3 - result of analysis.

\begin{tabular}{|c|c|c|c|c|c|c|c|}
\hline \multirow[t]{2}{*}{ BOR1 } & \multirow{2}{*}{$\begin{array}{c}\sigma_{0} \\
\mathrm{~N}, \mathrm{E}, \mathrm{U} \\
{[\mathrm{mm}]}\end{array}$} & \multicolumn{3}{|c|}{$\begin{array}{c}\text { linear trend }[\mathrm{mm} / \mathrm{y}] \\
\text { NET solution } 1996.1-2012.1\end{array}$} & \multicolumn{3}{|c|}{ amplitude of annual period $[\mathrm{mm}]$} \\
\hline & & $\mathrm{N}$ & $\mathrm{E}$ & $\mathrm{U}$ & $\mathrm{N}$ & $\mathrm{E}$ & $\mathrm{U}$ \\
\hline NET & $3.8,2.9,6.3$ & 14.5 & 20.3 & -0.1 & - & - & - \\
\hline PPP & $2.1,3.4,5.5$ & 14.8 & 19.7 & -0.1 & - & - & 5.4 \\
\hline diference & & -0.3 & 0.6 & 0.0 & \multicolumn{3}{|c|}{ long periodic changes } \\
\hline
\end{tabular}


Table 4 result of analysis.

\begin{tabular}{ccccccccc}
\hline \multirow{2}{*}{ DRES } & $\sigma_{0}$ & \multicolumn{3}{c}{ linear trend $[\mathrm{mm} / \mathrm{y}]$} & \multicolumn{3}{c}{ amplitude of annual period [mm] } \\
\cline { 3 - 8 } & $\mathrm{N}, \mathrm{E}, \mathrm{U}$ & \multicolumn{2}{c}{ NET solution $2003.1-2012.1$} & $\mathrm{~N}$ & $\mathrm{E}$ & $\mathrm{U}$ \\
\cline { 3 - 8 } & {$[\mathrm{mm}]$} & $\mathrm{N}$ & $\mathrm{E}$ & $\mathrm{U}$ & $\mathrm{N}$ & 1.3 & 1.8 & 2.6 \\
NET & $2.5,2.2,6.5$ & 15.6 & 19.8 & -0.8 & & 6.6 \\
PPP & $1.9,3.4,7.3$ & 15.7 & 20.4 & -0.4 & 1.1 & - & --- \\
diference & & -0.1 & -0.6 & -0.4 & & \\
\hline
\end{tabular}

Table 5 result of analysis.

\begin{tabular}{|c|c|c|c|c|c|c|c|}
\hline \multirow[t]{2}{*}{ GOPE } & \multirow{2}{*}{$\begin{array}{c}\sigma_{0} \\
\mathrm{~N}, \mathrm{E}, \mathrm{U} \\
{[\mathrm{mm}]}\end{array}$} & \multicolumn{3}{|c|}{$\begin{array}{l}\text { linear trend }[\mathrm{mm} / \mathrm{y}] \\
\text { NET solution } 2000.0-2008.0\end{array}$} & \multicolumn{3}{|c|}{ amplitude of annual period [mm] } \\
\hline & & $\mathrm{N}$ & $E$ & $\mathrm{U}$ & $\mathrm{N}$ & $\mathrm{E}$ & $\mathrm{U}$ \\
\hline NET & $2.6,2.4,5.8$ & 15.5 & 19.8 & 1.7 & - & - & 2.1 \\
\hline PPP & $1.8,2.8,5.8$ & 16.4 & 19.0 & 0.8 & - & - & 5.2 \\
\hline diference & & 0.9 & 0.8 & 0.9 & \multicolumn{3}{|c|}{ long periodic changes } \\
\hline
\end{tabular}

Table 6 - result of analysis.

\begin{tabular}{|c|c|c|c|c|c|c|c|}
\hline \multirow[t]{2}{*}{ GRAZ } & \multirow{2}{*}{$\begin{array}{c}\sigma_{0} \\
\mathrm{~N}, \mathrm{E}, \mathrm{U} \\
{[\mathrm{mm}]}\end{array}$} & \multicolumn{3}{|c|}{$\begin{array}{c}\text { linear trend }[\mathrm{mm} / \mathrm{y}] \\
\text { NET solution } 1996.1-2012.1\end{array}$} & \multicolumn{3}{|c|}{ amplitude of annual period $[\mathrm{mm}]$} \\
\hline & & $\mathrm{N}$ & $\mathrm{E}$ & $\mathrm{U}$ & $\mathrm{N}$ & $\mathrm{E}$ & $\mathrm{U}$ \\
\hline NET & $4.0,2.9,6.5$ & 15.8 & 21.8 & 0.5 & - & - & 2.3 \\
\hline PPP & $2.5,3.6,6.2$ & 15.8 & 21.8 & 0.9 & - & - & 6.5 \\
\hline diference & & 0.0 & 0.0 & -0.4 & \multicolumn{3}{|c|}{ long periodic changes } \\
\hline
\end{tabular}

Table 7 -result of analysis.

\begin{tabular}{|c|c|c|c|c|c|c|c|}
\hline \multirow{2}{*}{ HERS } & \multirow{2}{*}{$\begin{array}{c}\sigma_{0} \\
\mathrm{~N}, \mathrm{E}, \mathrm{U} \\
{[\mathrm{mm}]}\end{array}$} & \multicolumn{3}{|c|}{$\begin{array}{c}\text { linear trend }[\mathrm{mm} / \mathrm{y}] \\
\text { NET solution } 2001.7-2010.7\end{array}$} & \multicolumn{3}{|c|}{ amplitude of annual period $[\mathrm{mm}]$} \\
\hline & & $\mathrm{N}$ & $\mathrm{E}$ & $\mathrm{U}$ & $\mathrm{N}$ & $\mathrm{E}$ & $\mathrm{U}$ \\
\hline NET & $3.1,2.8,9.0$ & 16.6 & 16.8 & 0.6 & 0.9 & 0.9 & 1.8 \\
\hline PPP & $2.0,2.7,4.8$ & 16.4 & 16.5 & 0.5 & - & - & 4.8 \\
\hline diference & & 0.2 & 0.3 & 0.1 & \multicolumn{3}{|c|}{ long periodic changes } \\
\hline
\end{tabular}

Table 8 - result of analysis.

\begin{tabular}{|c|c|c|c|c|c|c|c|}
\hline \multirow[t]{2}{*}{ HFLK } & \multirow{2}{*}{$\begin{array}{c}\sigma_{0} \\
\mathrm{~N}, \mathrm{E}, \mathrm{U} \\
{[\mathrm{mm}]}\end{array}$} & \multicolumn{3}{|c|}{$\begin{array}{l}\text { linear trend }[\mathrm{mm} / \mathrm{y}] \\
\text { NET solution } 1996.1-2003.2\end{array}$} & \multicolumn{3}{|c|}{ amplitude of annual period [mm } \\
\hline & & $\mathrm{N}$ & $\mathrm{E}$ & $\mathrm{U}$ & $\mathrm{N}$ & E & $\mathrm{U}$ \\
\hline NET & $4.3,3.7,7.2$ & 16.8 & 21.5 & 4.0 & 4.0 & 2.4 & 3.1 \\
\hline PPP & $2.5,5.2,6.2$ & 15.8 & 21.3 & 2.1 & 5.3 & 3.1 & 6.3 \\
\hline diference & & 1.0 & 0.2 & 1.9 & & --- & \\
\hline
\end{tabular}

Table 9 - result of analysis.

\begin{tabular}{|c|c|c|c|c|c|c|c|}
\hline \multirow[t]{2}{*}{ KIRU } & \multirow{2}{*}{$\begin{array}{c}\sigma_{0} \\
\mathrm{~N}, \mathrm{E}, \mathrm{U} \\
{[\mathrm{mm}]}\end{array}$} & \multicolumn{3}{|c|}{$\begin{array}{c}\text { linear trend }[\mathrm{mm} / \mathrm{y}] \\
\text { NET solution } 1996.1-2011.1\end{array}$} & \multicolumn{3}{|c|}{ amplitude of annual period [mm] } \\
\hline & & $\mathrm{N}$ & $\mathrm{E}$ & $\mathrm{U}$ & $\mathrm{N}$ & $\mathrm{E}$ & $\mathrm{U}$ \\
\hline NET & $6.8,3.9,13.1$ & 15.0 & 15.8 & 6.9 & 1.7 & - & $\begin{array}{c}6.9 \\
\text { semi } 4.0\end{array}$ \\
\hline PPP & $4.1,4.3,13.4$ & 15.1 & 15.5 & 7.3 & - & - & $\begin{array}{c}7.2 \\
\text { semi } 7.4\end{array}$ \\
\hline diference & & -0.1 & 0.3 & -0.4 & \multicolumn{3}{|c|}{ long periodic changes } \\
\hline
\end{tabular}


Table 10 - result of analysis.

\begin{tabular}{|c|c|c|c|c|c|c|c|}
\hline \multirow[t]{2}{*}{ NICO } & \multirow{2}{*}{$\begin{array}{c}\sigma_{0} \\
\mathrm{~N}, \mathrm{E}, \mathrm{U} \\
{[\mathrm{mm}]}\end{array}$} & \multicolumn{3}{|c|}{$\begin{array}{c}\text { linear trend }[\mathrm{mm} / \mathrm{y}] \\
\text { NET solution } 1999.7-2006.5\end{array}$} & \multicolumn{3}{|c|}{ amplitude of annual period [mm } \\
\hline & & $\mathrm{N}$ & $E$ & $\mathrm{U}$ & $\mathrm{N}$ & $E$ & $\mathrm{U}$ \\
\hline NET & $4.6,4.8,9.3$ & 15.4 & 19.9 & -0.5 & 2.8 & - & 3.9 \\
\hline PPP & $2.5,3.9,7.2$ & 15.5 & 19.0 & 0.2 & 1.7 & - & 5.8 \\
\hline diference & & -0.1 & 0.9 & -0.7 & & --- & \\
\hline
\end{tabular}

Table 11 - result of analysis.

\begin{tabular}{cccccccc}
\hline \multirow{2}{*}{ ONSA } & $\sigma_{0}$ & \multicolumn{3}{c}{ linear trend $[\mathrm{mm} / \mathrm{y}]$} & \multicolumn{2}{c}{ amplitude of annual period [mm] } \\
\cline { 3 - 7 } & $\mathrm{N}, \mathrm{E}, \mathrm{U}$ & \multicolumn{2}{c}{$\mathrm{NET}$ solution $1996.1-2012.1$} & $\mathrm{U}$ & $\mathrm{E}$ \\
\hline $\mathrm{NET}$ & $3.4,2.7,5.6$ & 14.5 & 17.0 & 2.3 & - & - & 1.5 \\
PPP & $2.3,3.9,6.4$ & 14.5 & 16.8 & 2.8 & - & - & 4.3 \\
\cline { 3 - 7 } diference & & 0.0 & 0.2 & -0.5 & \multicolumn{2}{c}{ long periodic changes } \\
\hline
\end{tabular}

Table 12 - result of analysis.

\begin{tabular}{cccccccc}
\hline \multirow{2}{*}{ POTS } & $\sigma_{0}$ & \multicolumn{3}{c}{ linear trend $[\mathrm{mm} / \mathrm{y}]$} & & \multicolumn{2}{c}{ amplitude of annual period [mm] } \\
& $\mathrm{N}, \mathrm{E}, \mathrm{U}$ & \multicolumn{2}{c}{ NET solution $1996.1-2012.1$} & \multicolumn{2}{c}{$\mathrm{U}$} \\
\cline { 3 - 7 } & {$[\mathrm{mm}]$} & $\mathrm{N}$ & $\mathrm{E}$ & $\mathrm{U}$ & $\mathrm{N}$ & $\mathrm{E}$ & 2.0 \\
NET & $3.3,2.8,6.1$ & 15.2 & 19.0 & -0.2 & - & - & 5.2 \\
PPP & $3.9,4.5,6.1$ & 15.2 & 18.9 & 0.2 & - & - \\
\cline { 4 - 7 } diference & & 0.0 & 0.1 & -0.4 & & long periodic changes \\
\hline
\end{tabular}

Table 13 - result of analysis.

\begin{tabular}{|c|c|c|c|c|c|c|c|}
\hline \multirow[t]{2}{*}{ REYK } & \multirow{2}{*}{$\begin{array}{c}\sigma_{0} \\
\mathrm{~N}, \mathrm{E}, \mathrm{U} \\
{[\mathrm{mm}]}\end{array}$} & \multicolumn{3}{|c|}{$\begin{array}{c}\text { linear trend }[\mathrm{mm} / \mathrm{y}] \\
\text { NET solution } 1996.1-2012.1\end{array}$} & \multicolumn{3}{|c|}{ amplitude of annual period [mm] } \\
\hline & & $\mathrm{N}$ & $\mathrm{E}$ & $\mathrm{U}$ & $\mathrm{N}$ & $\mathrm{E}$ & $\mathrm{U}$ \\
\hline NET & $4.4,5.4,9.0$ & 20.7 & -10.8 & -1.3 & - & 2.6 & 7.9 \\
\hline PPP & $2.9,4.6,10.1$ & 20.8 & -11.5 & -2.6 & - & 2.8 & 3.4 \\
\hline diference & & -0.1 & -0.3 & 1.3 & \multicolumn{3}{|c|}{ long periodic changes } \\
\hline
\end{tabular}

Table 14 - result of analysis.

\begin{tabular}{|c|c|c|c|c|c|c|c|}
\hline \multirow[t]{2}{*}{ TUBI } & \multirow{2}{*}{$\begin{array}{c}\sigma_{0} \\
\mathrm{~N}, \mathrm{E}, \mathrm{U} \\
{[\mathrm{mm}]}\end{array}$} & \multicolumn{3}{|c|}{$\begin{array}{c}\text { linear trend }[\mathrm{mm} / \mathrm{y}] \\
\text { NET solution } 1999.8-2012.1\end{array}$} & \multicolumn{3}{|c|}{ amplitude of annual period [mm] } \\
\hline & & $\mathrm{N}$ & $\mathrm{E}$ & $\mathrm{U}$ & $\mathrm{N}$ & $\mathrm{E}$ & $\mathrm{U}$ \\
\hline NET & $4.3,4.1,7.7$ & 10.0 & 23.7 & -1.9 & $\begin{array}{c}1.7 \\
\text { semi } 1.0\end{array}$ & 2.7 & 4.7 \\
\hline PPP & $2.1,3.2,6.2$ & 9.1 & 23.6 & -1.5 & - & - & 5.4 \\
\hline diference & & 0.9 & 0.1 & -0.4 & \multicolumn{3}{|c|}{ long periodic changes } \\
\hline
\end{tabular}

Table 15 - result of analysis.

\begin{tabular}{|c|c|c|c|c|c|c|c|}
\hline \multirow[t]{2}{*}{ WTZR } & \multirow{2}{*}{$\begin{array}{c}\sigma_{0} \\
\mathrm{~N}, \mathrm{E}, \mathrm{U} \\
{[\mathrm{mm}]}\end{array}$} & \multicolumn{3}{|c|}{$\begin{array}{c}\text { linear trend }[\mathrm{mm} / \mathrm{y}] \\
\text { NET solution } 2000.0-2008.0\end{array}$} & \multicolumn{3}{|c|}{ amplitude of annual period [mm } \\
\hline & & $\mathrm{N}$ & $E$ & $\mathrm{U}$ & $\mathrm{N}$ & $\mathrm{E}$ & $\mathrm{U}$ \\
\hline NET & $3.2,2.7,6.1$ & 15.4 & 20.4 & 0.0 & - & - & 2.0 \\
\hline PPP & $2.1,3 \cdot 1,5.7$ & 15.7 & 20.2 & -0.1 & - & - & 5.2 \\
\hline diference & & -0.3 & 0.2 & 0.1 & \multicolumn{3}{|c|}{ long periodic changes } \\
\hline
\end{tabular}




\section{CONCLUSIONS}

Summarizing the obtained results we get the values given in Table 16.

Table 16 Summarized values.

\begin{tabular}{cccc}
\hline difference & \multicolumn{3}{c}{ value $\mathrm{mm} / \mathrm{y}$} \\
& mean & $\min$ & $\max$ \\
\hline $\mathrm{dN}$ & 0.43 & -0.3 & 0.9 \\
$\mathrm{dE}$ & 0.39 & -0.6 & 0.9 \\
$\mathrm{dU}$ & 0.74 & -0.7 & 1.3 \\
\hline
\end{tabular}

It is possible to state that for the PPP solution the statistically significant amplitude of the annual term in the height component $U$ occurs at each station. For the network solution the corresponding amplitude is smaller which can be explained by phase-consonant periodical changes of heights of the fiducial stations which are used in the network solution.

The majority of stations also display significant long-periodic (greater than one year) changes of some of coordinates which may indicate that the linear approximation of the trend might be insufficient.

From the obtained results it can be inferred that a) from statistical point of view (dispersion of value with respect to value) the differences of the results are in many cases statistically significant, b) the annual variations of the vertical component, determined by PPP method have real basis according meaning of geomorfologists - see i.e. (Kalvoda, 2015) and c) the differences in the trend of coordinate changes resulting from two processing methods cannot be neglected and might, in some way, influence geodynamical interpretations.

\section{ACKNOWLEDGEMENT}

This contribution was made possible thanks to the project TB01CUZK006 of TA ČR. Data for the GOPE station was taken via project LM2010008 CzechGeo EPOS.

\section{REFERENCES}

Kalvoda, J.: 2015, private communication.

Kostelecký, J. and Karský, G.: 1987, Analysis of $1970-$ 1983 circumzenithal measurements. Bull. Astron. Inst. Czechosl., 38, 16-23.

Vondrák, J.: 1970, The new circumzenithal of the Research Institute for Geodesy, Topography and Cartography in Prague. Bull. Astron. Inst. Czechosl., 21, No. 4, 264.

Vondrák, J.: 1977, The rotation of the Earth between 1955.5 and 1976.5 Studia geophys. geod., 21, No. 2, 107117.

Wells, D.E. and Vaníček, P.: 1978, Least Squares Spectral Analysis. Bedford Institute of Oceanography, Dartmouth, Canada, 43 pp. 